\title{
Best Paper Award
}

(C) ASM International 2016

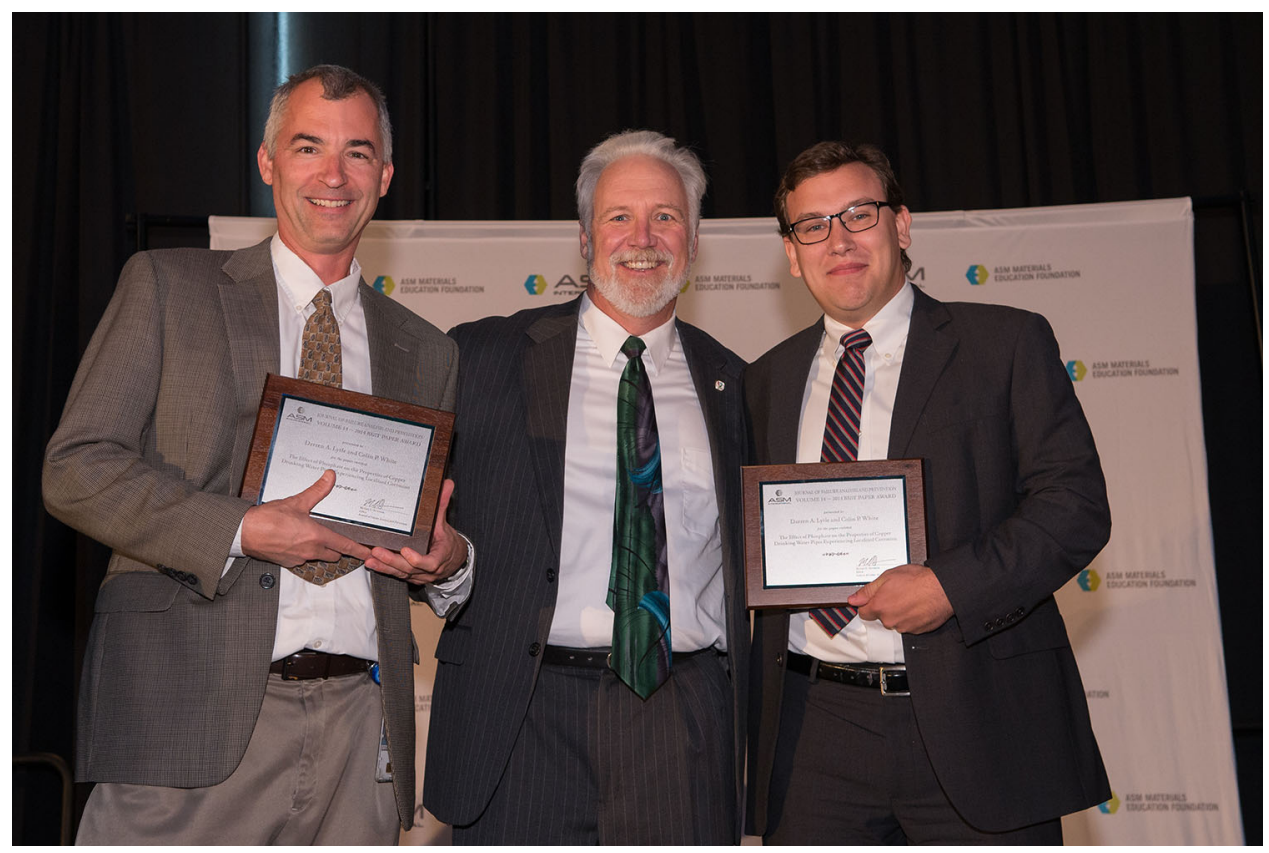

Jon Tirpak, President, ASM International (middle), presents the Volume 14 JFAP Best Paper Award plaques to Darren A. Lytle (left) and Colin P. White (right) during MS\&T '15

Dr. Michael E. Stevenson, editor of the Journal of Failure Analysis and Prevention (JFAP), announced that the JFAP Volume 14 Best Paper is "The Effect of Phosphate on the Properties of Copper Drinking Water Pipes Experiencing Localized Corrosion', by Darren A. Lytle and Colin P. White. The winning article was published in the April 2014 issue of JFAP.
The JFAP Volume 14 Best Paper Award was presented during the 2015 Leadership Awards Luncheon at MS\&T ' 15 in Columbus, Ohio, on October 5, 2015.

The award, in addition to the recognition, includes a plaque and $\$ 1000$ worth of ASM International products and services. The Best Paper was selected by the Editorial Board of the journal from all papers published in volume 14 . 